J. Dairy Sci. 95:6529-6535

http://dx.doi.org/10.3168/jds.2012-5748

(C) American Dairy Science Association ${ }^{\circledR}, 2012$.

\title{
MicroRNA expression patterns in the bovine mammary gland are affected by stage of lactation ${ }^{1}$
}

\author{
M. Wang, ${ }^{*} †$ S. Moisá, $†$ M. J. Khan, $†$ J. Wang, ${ }^{* 2}$ D. Bu, ${ }^{*}$ and J. J. Loor ${ }^{2}$ \\ *State Key Laboratory of Animal Nutrition, Institute of Animal Science, Chinese Academy of Agricultural Sciences, Beijing 100193, P. R. China \\ †Mammalian NutriPhysioGenomics, Division of Nutritional Sciences, 498 Animal Science Laboratory, Department of Animal Sciences, \\ University of Illinois, Urbana 61801
}

\section{ABSTRACT}

The objective of this work was to determine the expression pattern of microRNA (miR) associated with cellular proliferation, lipid metabolism, and innate immunity in dairy cow mammary gland tissue at different stages of lactation. The expression of miR-10a, miR-15b, miR-16, miR-21, miR-31, miR-33b, miR-145, miR-146b, miR-155, miR-181a, miR-205, miR-221, and miR-223 was studied by real-time reverse-transcription $\mathrm{PCR}$ in tissue ( $\mathrm{n}=7 /$ stage) harvested via repeated biopsies during the dry period ( $-30 \mathrm{~d}$ prepartum), the fresh period ( $7 \mathrm{~d}$ postpartum), and early lactation (30 d postpartum). Except for miR-31, all miR studied increased in expression between the dry and fresh periods. Among those upregulated, the expression of miR-221 increased further at early lactation, suggesting a role in the control of endothelial cell proliferation or angiogenesis, whereas the expression of miR-223 decreased at early lactation but to a level that was greater than in the dry period, suggesting it could play a role in the mammary response to pathogens soon after parturition. The expression of miR-31, a hormonally regulated miR that inhibits cyclin gene expression, was greater at early lactation compared with the dry period. From a metabolic standpoint, the consistent upregulation of miR-33b during early lactation compared with the dry period suggests that this miR may exert some control over lipogenesis in mammary tissue. Overall, results indicate that expression of $\mathrm{miR}$ associated with transcriptional regulation of genes across diverse biological functions is altered by stage of lactation. The specific roles of these miR during lactation will require further research.

\footnotetext{
Received May 18, 2012.

Accepted July 26, 2012.

${ }^{1}$ Financial support for the study was provided by the National Key Basic Research Program of China (project number 2011CB100805) and by the Cooperative State Research, Education and Extension Service (USDA, Washington, DC; project number ILLU-538-307).

${ }^{2}$ Corresponding authors: jqwangcaas@gmail.com and jloor@illinois.
}

Key words: dairy cow, mammary gland, lactation, microribonucleic acid

\section{INTRODUCTION}

MicroRNA (miR) are small noncoding RNA that regulate gene expression posttranscriptionally and play a key role in development and specific biological processes, such as cell proliferation, differentiation, and apoptosis, in several species (Filipowicz et al., 2008). Work in the mouse recently revealed that tissues have a specific miRNome pattern of expression, that is, a full complement of miR (Liu et al., 2004). The human breast-specific signature is characterized by the expression of 23 miR (miR-let-7a-1, miR-let-7b, miR-023a, miR-023b, miR-024-2, miR-026a, miR-026b, miR-030b, miR-030c, miR-030d, miR-092-1, miR-092-2, miR-1001/2, miR-103-1, miR-107, miR-146, miR-191, miR-197, miR-205, miR-206, miR-213, miR-214, and miR-221) out of 161 studied (Liu et al., 2004), and the mouse mammary-specific signature is characterized by the expression of $9 \mathrm{miR}$ (miR-let-7a, miR-let-7b, miR-let-7c, miR- 26a, miR-26b, miR-24-2, miR-145, miR-30b, and miR-30d) out of 22 detected (Silveri et al., 2006), suggesting that miR could play a role in mammary gland physiology.

The mammary gland is unique in its capability to undergo cycles of cell proliferation, differentiation, and apoptosis during adult life. The complex regulation of mammary development has been extensively studied over the years at the genetic, physiological, and morphological levels (Anderson et al., 2007). Because of the relatively recent recognition of $\mathrm{miR}$ as key regulators of cellular function, only a few reports have focused on the role of miR in normal mammary development. To our knowledge, the longitudinal changes in miR expression profiles during different stages of lactation have been evaluated only in the mouse (Silveri et al., 2006). Therefore, knowledge of the expression patterns of miR in the bovine mammary gland during the transition from pregnancy into lactation might provide insight into their roles in such functions as regulation of me- 
tabolism, angiogenesis, differentiation and apoptosis, and the immune response.

The general hypothesis of the present study was that the expression of selected miR associated with cellular proliferation, metabolism, and innate immune response differs between the dry period and lactation. Furthermore, such patterns of expression may be associated with the mRNA expression of metabolic (Bionaz and Loor, 2008, 2011), cell proliferation and apoptosis (Annen et al., 2008), angiogenesis (Mattmiller et al., 2011), apoptosis, and immune or stress-related genes (Aitken et al., 2009). Therefore, the main objective of this work was to determine the expression pattern of several important miR in the Holstein cow mammary gland at different stages of the lactation cycle (dry period, fresh period after calving, and early lactation), and to provide the basis for selection of candidate $\mathrm{miR}$ for more detailed functional characterization in the future.

\section{MATERIALS AND METHODS}

All procedures involving animals received approval from the Institutional Animal Care and Use Committee at the University of Illinois, Urbana (protocol 06145). The right rear quarter of 7 cows was biopsied at -30 and $30 \mathrm{~d}$, and the left rear quarter was biopsied at 7 d. The midsections of the rear quarters were selected for the initial biopsy. Subsequently, a different section located approximately $5 \mathrm{~cm}$ from the original incision site of the right quarter was selected for biopsy. Biopsies were conducted at approximately $0700 \mathrm{~h}$ (after the morning milking). Briefly, after the skin incision was made, blunt dissection of the mammary capsule was performed to ensure the tissue obtained during the biopsy was mammary parenchyma; that is, biopsies were performed once the view of the mammary capsule was clear such that the tip of the biopsy tool could go through the dissected connective tissue. Immediately after removal of the biopsy instrument from the capsule, pressure was applied to the wound until visual signs of bleeding were absent. The skin incision was closed with 4 or 5 Michel clips (11 mm; Henry Schein, Melville, NY). The incision site was sprayed with topical antiseptic (10\% Povidone Iodine Ointment; Taro Pharmaceuticals, Hawthorne, NY).

Samples were frozen in liquid nitrogen within $30 \mathrm{~s}$ after tissue dissection. Frozen samples were stored at $-80^{\circ} \mathrm{C}$. Later, mammary gland tissue $(100 \mathrm{mg})$ was homogenized in lysis/binding buffer with $1 / 10$ vol of homogenate additive (mir-Vana miRNA Isolation Kit, AM1561; Applied Biosystems, Foster City, CA) using a Tissue-Tearor (BioSpec Products, Bartlesville, OK) homogenizer. After prehomogenizing samples at 10,000 rpm at $4^{\circ} \mathrm{C}$ for $10 \mathrm{~min}$ to remove fat and cell debris, miR were extracted from the supernatant according to the manufacturer's protocol (mir-Vana miRNA Isolation Kit, AM1561; Applied Biosystems). Ribonucleic acid $(10 \mu \mathrm{g})$ was polyadenylated using Poly(A) polymerase according to the manufacturer's instructions (NCode miRNA, First Strand cDNA Module, no. 45-6612; Invitrogen, Foster City, CA). Complementary DNA was made as follows: $10 \mu \mathrm{g}$ of polyadenylated RNA was reverse-transcribed using Superscript II reverse transcriptase (Invitrogen) with $2.5 \mu \mathrm{g}$ of random hexamers and $500 \mathrm{ng}$ of oligo(dT) adapter primer (Invitrogen), according to the manufacturer's instructions.

The reactions were performed in triplicate as follows: $5 \mu \mathrm{L}$ of cDNA were mixed with 5 pmol of both the forward $(\mathrm{F})$ and reverse $(\mathrm{R})$ primers in a final volume of $12.5 \mu \mathrm{L}$ and mixed with $12.5 \mu \mathrm{L}$ of $2 \times$ Power SYBR Green PCR Master Mix (No. 4367659; Applied Biosystems). All reactions were run using 2 amplification protocols: $20 \mathrm{~s}$ at $94^{\circ} \mathrm{C}, 30 \mathrm{~s}$ at $59^{\circ} \mathrm{C}$, and $20 \mathrm{~s}$ at $72^{\circ} \mathrm{C}$ for 40 cycles. The same conditions were performed on an equal amount of RNase-free water as a negative control. Primer sequences were as follows: miR-10a-F: ACCCTGTAGATCCGAATTTGTG (NR_031364.1); miR-145-F: CCAGTTTTCCCAGGAATCCCT (NR_030906.1); miR-146b-F: TGAGAACTGAATTCCATAGGC (NR_031033.1); miR-155-F: TTAATGCTAATCGTGATAGGGG (NR_031030.1); miR-15b-F: TAGCAGCACATCATGGTTTACA (NR_031363.1); miR-16-F: TAGCAGCACGTAAATATTGGC (NR_030891.1); miR-181a-F: ATTCAACGCTGTCGGTGAGTT (NR_031081.1); miR-205-F: TCCTTCATTCCACCGGAGTCT (NR_030909.1); miR-21-F: GCTTATCAGACTGATGTTGACT (NR_030880.1); miR-221-F: AGCTACATTGTCTGCTGGGTTT (NR_030881.1); miR223-F: TGTCAGTTTGTCAAATACCCCA (NR_031144.1); miR-31-F: AGGCAAGATGCTGGCATAGCT (DQ274883.1); miR-33b-F: GTGCATTGCTGTTGCATTG (NR_031207.1); U6 (internal control miR)-F: CGCTTCGGCAGCACATATAC; and U6-R: TCACGAATTTGCGTGTCAT. We also analyzed expression of miR-146a, miR-17, and miR-33a; they were undetectable under the conditions used and will not be discussed further. Real-time quantitative PCR with SYBR Green I (Power SYBR Green, PCR Master Mix, No. 4367659; Applied Biosystems) was performed in an ABI Prism 7900 HT SDS instrument (Applied Biosystems), and the data were calculated with 7900 HT Sequence Detection Systems software (version 2.2.1; Applied Biosystems). The geometric mean of 5S (catalog no. AM30302; Applied Biosystems) and U6 was used to normalize the expression of target miR (Gandellini et al., 2009; Xu et al., 2010). 

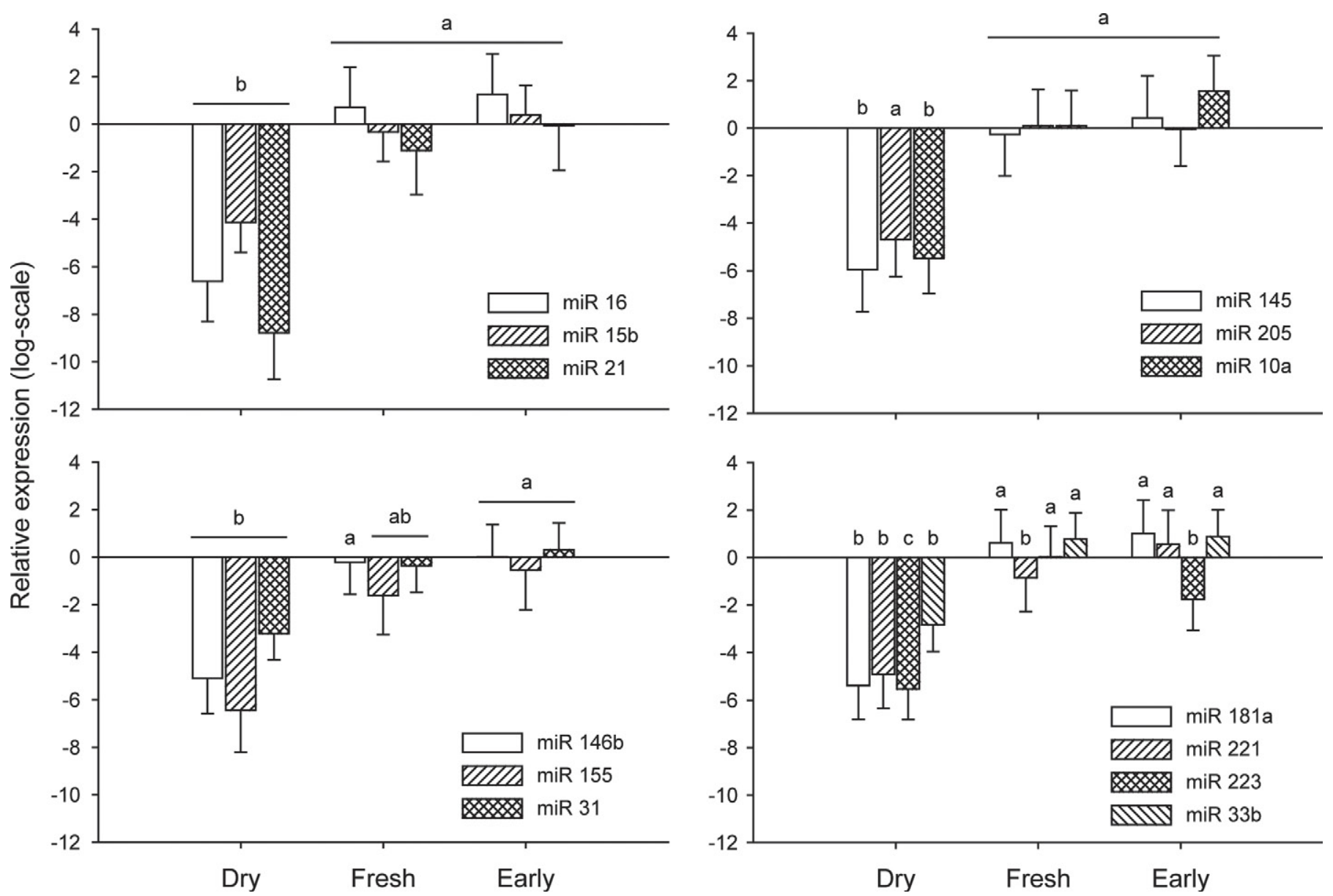

Figure 1. Expression of microRNA (miR) in mammary gland tissue of Holstein cows $(\mathrm{n}=7 /$ stage) during the dry period $(-30 \mathrm{~d}$ prepartum), fresh period $(7 \mathrm{~d}$ postpartum), or early lactation $(30 \mathrm{~d}$ postpartum). Lowercase letters $(\mathrm{a}-\mathrm{c})$ denote differences $(P \leq 0.07)$ between stages of lactation.

Normalized miR expression data were $\log _{2}$-transformed before statistical analysis by using repeated measures ANOVA with the MIXED procedure of SAS (SAS Institute, Cary, NC) to determine the overall effect of stage of lactation. The fixed effect considered in the model was stage of lactation, and cow represented the random effect. Compound symmetry was used as a covariate structure for repeated measures. The expression values and standard errors of the means in Figure 1 are reported as $\log _{2}$-transformed values. Means were accepted as significant at $P \leq 0.07$. Differences between means at the time points examined were evaluated using the PDIFF statement in SAS. The percentage relative abundance among each miR analyzed was calculated as reported previously to aid in biological interpretation of the changes observed (Bionaz and Loor, 2008). Evaluation of miR target genes in mammary tissue at $30 \mathrm{~d}$ postpartum was conducted via Ingenuity Pathway Analysis (Ingenuity Systems Inc., Redwood City, CA) using the list of genes reported recently with differential expression at 30 versus $-30 \mathrm{~d}$ relative to parturition (Bionaz et al., 2012).

\section{RESULTS AND DISCUSSION}

Results indicated that 12 of the $13 \mathrm{miR}$ evaluated had lower $(P \leq 0.07)$ expression in the dry period compared with the fresh period and early lactation. The only exception was miR-31, whose expression was similar in the dry period compared with the fresh period, but was greater at early lactation than in the dry period $(P$ $\leq 0.07$ ). These results differed from those with mice, which demonstrated an approximately 2-fold decrease in miR expression during lactation and the early stages of involution (i.e., 12, 24, and $48 \mathrm{~h}$ after pup removal) relative to pregnancy (Avril-Sassen et al., 2009). One probable reason for these different responses might be the existence of inherent species differences, such as differences in the relative proportion of secretory epithelium and adipocytes in the cow versus the mouse on 
a tissue weight basis (Gu et al., 2007; Avril-Sassen et al., 2009).

In the context of cattle, the marked upregulation of most miR studied coincided with a dramatic change in the number of genes with altered expression at -15 through $30 \mathrm{~d}$ compared with $-30 \mathrm{~d}$ relative to parturition (Bionaz et al., 2012). Bioinformatic analysis of those data, particularly responses at 30 compared with $-30 \mathrm{~d}$, revealed activation of pathways associated with metabolism (e.g., lipids, amino acids, carbohydrates), cell motility, cell communication, and the immune system (Bionaz et al., 2012). In contrast, pathways associated with gene transcription, cell motility, and growth or death were inhibited at $30 \mathrm{~d}$ compared with $-30 \mathrm{~d}$ (Bionaz et al., 2012).

It is plausible that upregulation of miR at the onset of lactation and through early lactation exerts some control over the differential expression of genes associated with the above-mentioned pathways. For instance, the greater expression of miR-31 and miR-33b at early lactation compared with the dry period could be associated with control over the cell cycle, milk ejection [OXTR (oxytocin receptor)], and energy metabolism. Although they accounted for 0.1 and $1 \%$ of the total miR evaluated, both have been associated with inhibition of cyclin gene expression in some cell types (Kuokkanen et al., 2010; Cirera-Salinas et al., 2012). MicroRNA-31 suppresses prometastatic target genes, including ITGA5 (integrin $\alpha 5$ ), $R D X$ (radixin), and $R h o A$ (Ras homolog gene family, member A; Valastyan et al., 2009, 2011). In addition, through control of CREG1 (cellular repressor of E1A-stimulated genes 1) expression (Table 1), miR-31 indirectly promotes cellular proliferation and inhibits differentiation (Moolmuang and Tainsky, 2011). Prior work with cattle has shown that mammary cell proliferation increases, whereas apoptosis decreases between the onset of lactation through at least $90 \mathrm{~d}$ postpartum (Capuco et al., 2001). Among the gene targets of miR-31 and miR-33b that were differentially expressed in mammary tissue at $30 \mathrm{~d}$ compared with $-30 \mathrm{~d}$ relative to parturition (Bionaz et al., 2012) are BTN1A1 (butyrophilin subfamily 1 member A1), GPAM (glycerol-3-phosphate acyltransferase 1, mitochondrial), and PRKAA2 (5'-AMP-activated protein kinase catalytic subunit $\alpha-2$; Table 1 ), which are involved in milk fat synthesis and intracellular energy metabolism (Bionaz and Loor, 2008; Bionaz et al., 2012), and also $S L C 39 A 8$ (solute carrier family 39, zinc transporter, member 8) and $H L A-A$ (human leukocyte antigen A), which are associated with immune responses (e.g., $\mathrm{Zn}^{2+}$ import in response to inflammation).

In addition to a role in cell cycle control, the consistent upregulation of miR-33b during the fresh period and early lactation versus the dry period in the current study suggests that this miR could exert some control over lipid metabolism in mammary tissue. The sterolresponsive element binding factor 1 (SREBF1), a lipogenic transcription regulator in rodents, contains a binding region for miR-33b, and it has been proposed that activation (i.e., transcription splicing) of miR-33b could enhance the abundance of SREBF1, leading to increased lipogenesis while at the same time inhibiting FA degradation (Rottiers and Naar, 2012). Additional work has revealed a role for miR-33a/b in the regulation of insulin signaling (Dávalos et al., 2011). We have shown previously that expression of $S R E B F 1$, $S R E B F 2$, and several components of the insulin signaling pathway is upregulated in bovine mammary tissue during lactation compared with the dry period (Bionaz and Loor, 2008, 2011). However, the fact that the relative percentage of abundance of miR-33b was $0.1 \%$ of total miR studied could be taken as indication of the lack of a mechanistic role in lactating mammary tissue. Because of the importance of milk fat and protein from a nutritional standpoint, additional work on miR-33b regulation seems warranted.

No difference $(P>0.07)$ in expression was observed between the fresh period and early lactation of miR10a, miR-145, miR-146b, miR-155, miR-15b, miR-16, miR-181a, miR-205, miR-21, miR-31, and miR-33b. From a molecular standpoint, it could be possible that the sustained expression of these miR is linked with the control of mRNA expression during the stages before peak lactation (Bionaz et al., 2012). The period between calving to approximately $30 \mathrm{~d}$ postpartum is associated with an increase in total tissue RNA (Capuco et al., 2001; Bionaz and Loor, 2007) but a progressive decline in the number of genes with altered expression relative to earlier stages of lactation, including the dry period (Bionaz et al., 2012). Other data showed a greater proportion of mammary epithelial tissue at 90 d compared with $14 \mathrm{~d}$ postpartum, which coincided with greater milk yield, lower apoptosis, and greater cell proliferation (Capuco et al., 2001). Thus, some of these miR might be associated with pathways of cell proliferation, apoptosis, or both.

The marked upregulation of miR-21 at $30 \mathrm{~d}$ compared with $-30 \mathrm{~d}$ coupled with its high abundance (16\% of total miR) and its control over JAG1 (jagged 1) and PTEN [phosphatase and tensin homolog, a negative regulator of $\mathrm{v}$-myc myelocytomatosis viral oncogene homolog (AKT) signaling; Table 1] suggest a mechanistic role of this miR in promoting mammary cell proliferation during early lactation (Capuco et al., 2001). Previous work demonstrated that downregulation of JAG1 inhibited cell growth and migration but induced apoptosis mediated in part by inactivation of the kinase and mammalian target of rapamycin signal- 
Table 1. MicroRNA (miR) studied and their target gene expression in mammary tissue from cows at $30 \mathrm{~d}^{\text {postpartum }}{ }^{1}$

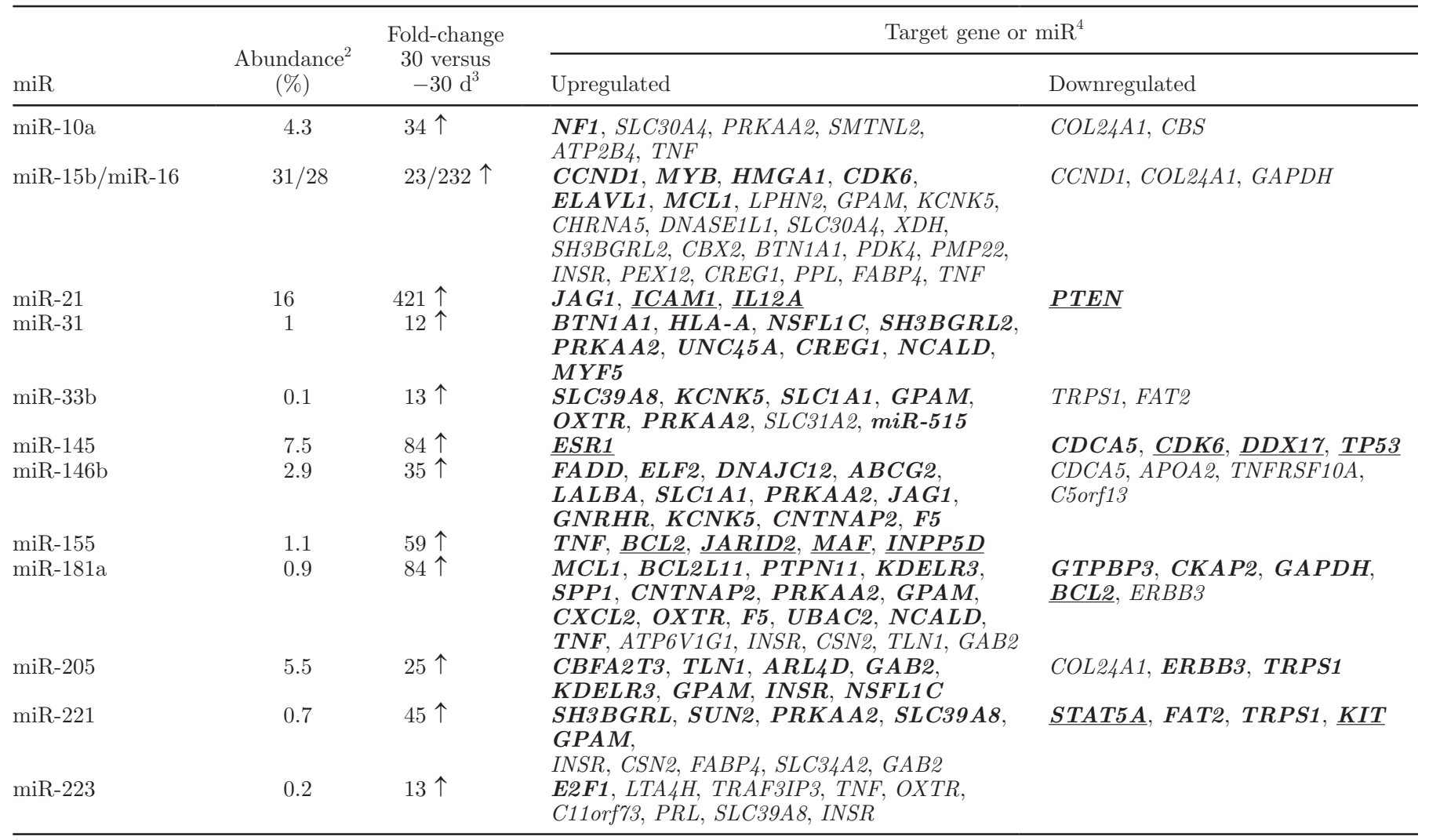

\footnotetext{
${ }^{1}$ Target genes are a subset of differentially expressed genes with 2-fold up- or downregulation at 30 versus -30 d relative to parturition. Molecules in bold denote direct targets of the miR, which in turn regulate expression of other targets listed. Bold and underlined molecules are direct targets with upregulated and downregulated expression by 2 -fold or greater.

${ }^{2}$ Percentage relative abundance among the miR measured in this study.

${ }^{3}$ Relative change in miR expression observed in this study.

${ }^{4}$ Determined using Ingenuity Pathway Analysis (Ingenuity Systems Inc., Redwood City, CA) and the list of differentially expressed genes with 2 -fold upregulation and 2 -fold downregulation at 30 versus -30 d relative to parturition in the study of Bionaz et al. (2012).
}

ing (Wang et al., 2010). We have previously demonstrated differential expression of AKT1 (v-akt murine thymoma viral oncogene homolog 1) and mammalian target of rapamycin signaling pathway genes in the mammary gland during the lactation cycle (Bionaz and Loor, 2011); thus, the existence of a mechanistic link with JAG1 and miR-21 is likely.

In murine smooth muscle cells, the upregulation of miR-10a is necessary for differentiation (Huang et al., 2010). This miR is highly conserved, and its localization in the vicinity of the $H O X$ (homeobox) gene cluster suggests it plays an important role in cellular development (Tehler et al., 2011), including that of mammary cells. Evidence exists that activation of $\mathrm{NF}_{\kappa} \mathrm{B}$ (nuclear factor $\kappa$ light-chain enhancer of activated $B$ cells) via p65 regulates miR-10a expression through direct binding to the miR promoter (Tehler et al., 2011), and we observed that expression of the miR-10a targets NF1 (neurofibromin 1) and TNF (tumor necrosis factor;
Table 1) was upregulated at $30 \mathrm{~d}$ postpartum, which suggests that this miR might exert some control over apoptosis and inflammation at peak lactation.

Our analysis revealed that ESR1 (estrogen receptor $\alpha$ ) is a target of miR-145 (Table 1 ) in bovine mammary tissue, suggesting that the network of ESR1, MYC (vmyc myelocytomatosis viral oncogene homolog), and TP53 (tumor protein 53), which is involved in mammary cell proliferation (Connor et al., 2007), might be controlled by miR upregulation. MicroRNA-145 suppressed cell proliferation, migration, and invasion in prostate cancer cells by targeting the actin-binding protein FSCN1 (fascin homolog 1, actin-bundling protein; Fuse et al., 2011). However, overexpression of this miR enhanced cellular motility.

MicroRNA-146b, miR-155, miR-15b, miR-16, and miR-181a (Tili et al., 2008) as well as miR-21 and miR205 (Kimura et al., 2010; Markou et al., 2008) are all involved in the innate and adaptive immune response, 
cell differentiation, and apoptosis in several cell types. Some of the target genes of these miR with marked upregulation in mammary tissue at $30 \mathrm{~d}$ postpartum (Table 1) included FADD (Fas-associated protein with death domain), TRAF6 (TNF receptor associated factor 6), TNF, BCL2 (B-cell lymphoma 2), and CXCL2 [chemokine (C-X-C motif) ligand 2], which play roles in the above biological processes.

Although, it is well established that morphological and transcriptional changes occur in the mammary glands of ruminants (Bionaz et al., 2012) and rodents (Anderson et al., 2007; Stein et al., 2007) during the transition between the different stages of lactation (i.e., virgin, pregnancy, lactation, and involution), prior work with the mouse indicated downregulation or little change in expression of miR-10a, miR-15b, miR-16, miR-21, miR-31, miR-145, and miR-33 but upregulation of miR-181a and miR-146b during lactation compared with gestation (Avril-Sassen et al., 2009). Clearly, those discrepancies must be related to speciesspecific functions of the miR; for example, cattle have been selected for sustained milk production. Together, these results suggest that these miR might have no direct implications for those lactation stages in the normal mammary gland. It could be speculated that the marked upregulation of the above-mentioned miR in bovine mammary tissue during lactation is functionally related to the changes in gene expression observed at peak lactation, which appear to encompass overall activation of signal transduction, cell communication, and the immune system (Bionaz et al., 2012).

The expression of miR-221 in early lactation was lower than that in peak lactation $(P \leq 0.07)$, and the reverse was true for miR-223. Unlike other miR studied, expression of miR-221 or miR-223 has not been reported previously in the context of lactation, and these miR accounted for 0.7 and $0.2 \%$ of the total miR analyzed (Table 1). MicroRNA-221 plays a role in cell growth and cell cycle progression by targeting p27 and p57 (Zhang et al., 2010), and 3 of its targets in mammary tissue are STAT5A (signal transducer and activator of transcription 5A), INSIG1 (insulin-induced gene 1), and PPARGC1A (peroxisome proliferator-activated receptor $\gamma$ coactivator $1-\alpha$ ), which are associated with insulin signaling, lipogenesis, and mitochondrial biogenesis during lactation (Bionaz and Loor, 2008, 2011). MicroRNA-223 is upregulated by the transcription repressor TWIST1 (twist homolog 1; Li et al., 2011) and is a potent suppressor of cell proliferation in noncancerous cells (Jia et al., 2011). Increased expression of miR-221 has been observed in several human cancers, supporting its function as an oncogene (Galardi et al., 2007; Gillies and Lorimer, 2007). It could be possible that the greater relative abundance of miR-221 com- pared with miR-223 and its greater fold change at 7 and 30 compared with $-30 \mathrm{~d}$ (45-fold compared with 13 -fold) is part of the control mechanism driving mammary cell proliferation during early lactation (Capuco et al., 2001).

In summary, we demonstrated upregulation of miR between late pregnancy, the fresh period, and early lactation, suggesting coregulation of these molecules as a mechanism to control gene expression in the mammary gland. Several metabolism-, cell proliferation-, apoptosis-, and immune response-associated genes were found to be potential targets of the miR studied. The exact mechanisms and functional consequences of miR regulation of mammary cell physiology during lactation warrant further investigation.

\section{REFERENCES}

Aitken, S. L., E. L. Karcher, P. Rezamand, J. C. Gandy, M. J. VandeHaar, A. V. Capuco, and L. M. Sordillo. 2009. Evaluation of antioxidant and proinflammatory gene expression in bovine mammary tissue during the periparturient period. J. Dairy Sci. 92:589-598.

Anderson, S. M., M. C. Rudolph, J. L. McManaman, and M. C. Neville. 2007. Key stages in mammary gland development. Secretory activation in the mammary gland: It's not just about milk protein synthesis! Breast Cancer Res. 9:204.

Annen, E. L., C. M. Stiening, B. A. Crooker, A. C. Fitzgerald, and R. J. Collier. 2008. Effect of continuous milking and prostaglandin E2 on milk production and mammary epithelial cell turnover, ultrastructure, and gene expression. J. Anim. Sci. 86:1132-1144.

Avril-Sassen, S., L. D. Goldstein, J. Stingl, C. Blenkiron, J. Le Quesne, I. Spiteri, K. Karagavriilidou, C. J. Watson, S. Tavare, E. A. Miska, and C. Caldas. 2009. Characterisation of microRNA expression in post-natal mouse mammary gland development. BMC Genomics 10:548.

Bionaz, M., and J. J. Loor. 2007. Identification of reference genes for quantitative real-time PCR in the bovine mammary gland during the lactation cycle. Physiol. Genomics 29:312-319.

Bionaz, M., and J. J. Loor. 2008. Gene networks driving bovine milk fat synthesis during the lactation cycle. BMC Genomics 9:366.

Bionaz, M., and J. J. Loor. 2011. Gene networks driving bovine mammary protein synthesis during the lactation cycle. Bioinform. Biol. Insights 5:83-98.

Bionaz, M., K. Periasamy, S. L. Rodriguez-Zas, R. E. Everts, H. A Lewin, W. L. Hurley, and J. J. Loor. 2012. Old and new stories: Revelations from functional analysis of the bovine mammary transcriptome during the lactation cycle. PLoS ONE 7:e33268.

Capuco, A. V., D. L. Wood, R. Baldwin, K. McLeod, and M. J. Paape. 2001. Mammary cell number, proliferation, and apoptosis during a bovine lactation: Relation to milk production and effect of bST. J. Dairy Sci. 84:2177-2187.

Cirera-Salinas, D., M. Pauta, R. M. Allen, A. G. Salerno, C. M. Ramirez, A. Chamorro-Jorganes, A. C. Wanschel, M. A. Lasuncion, M. Morales-Ruiz, Y. Suarez, A. Baldan, E. Esplugues, and C. Fernandez-Hernando. 2012. Mir-33 regulates cell proliferation and cell cycle progression. Cell Cycle 11:922-933.

Connor, E. E., M. J. Meyer, R. W. Li, M. E. Van Amburgh, Y. R. Boisclair, and A. V. Capuco. 2007. Regulation of gene expression in the bovine mammary gland by ovarian steroids. J. Dairy Sci. 90(E. Suppl. 1):E55-E65.

Dávalos, A., L. Goedeke, P. Smibert, C. M. Ramírez, N. P. Warrier, U. Andreo, D. Cirera-Salinas, K. Rayner, U. Suresh, J. C. PastorPareja, E. Esplugues, E. A. Fisher, L. O. Penalva, K. J. Moore, Y. Suárez, E. C. Lai, and C. Fernández-Hernando. 2011. miR-33a/b contribute to the regulation of fatty acid metabolism and insulin signaling. Proc. Natl. Acad. Sci. USA 108:9232-9237. 
Filipowicz, W., S. N. Bhattacharyya, and N. Sonenberg. 2008. Mechanisms of post-transcriptional regulation by microRNAs: Are the answers in sight? Nat. Rev. Genet. 9:102-114.

Fuse, M., N. Nohata, S. Kojima, S. Sakamoto, T. Chiyomaru, K. Kawakami, H. Enokida, M. Nakagawa, Y. Naya, T. Ichikawa, and N. Seki. 2011. Restoration of miR-145 expression suppresses cell proliferation, migration and invasion in prostate cancer by targeting FSCN1. Int. J. Oncol. 38:1093-1101.

Galardi, S., N. Mercatelli, E. Giorda, S. Massalini, G. V. Frajese, S. A. Ciafre, and M. G. Farace. 2007. miR-221 and miR-222 expression affects the proliferation potential of human prostate carcinoma cell lines by targeting p27Kip1. J. Biol. Chem. 282:23716-23724.

Gandellini, P., M. Folini, N. Longoni, M. Pennati, M. Binda, M. Colecchia, R. Salvioni, R. Supino, R. Moretti, P. Limonta, R. Valdagni, M. G. Daidone, and N. Zaffaroni. 2009. miR-205 exerts tumorsuppressive functions in human prostate through down-regulation of protein kinase Cepsilon. Cancer Res. 69:2287-2295.

Gillies, J. K., and I. A. Lorimer. 2007. Regulation of p27Kip1 by miRNA 221/222 in glioblastoma. Cell Cycle 6:2005-2009.

Gu, Z., S. Eleswarapu, and H. Jiang. 2007. Identification and characterization of microRNAs from the bovine adipose tissue and mammary gland. FEBS Lett. 581:981-988.

Huang, H., C. Xie, X. Sun, R. P. Ritchie, J. Zhang, and Y. E. Chen. 2010. miR-10a contributes to retinoid acid-induced smooth muscle cell differentiation. J. Biol. Chem. 285:9383-9389.

Jia, C. Y., H. H. Li, X. C. Zhu, Y. W. Dong, D. Fu, Q. L. Zhao, W. Wu, and X. Z. Wu. 2011. miR-223 suppresses cell proliferation by targeting IGF-1R. PLoS ONE 6:e27008.

Kimura, S., S. Naganuma, D. Susuki, Y. Hirono, A. Yamaguchi, S. Fujieda, K. Sano, and H. Itoh. 2010. Expression of microRNAs in squamous cell carcinoma of human head and neck and the esophagus: miR-205 and miR-21 are specific markers for HNSCC and ESCC. Oncol. Rep. 23:1625-1633.

Kuokkanen, S., B. Chen, L. Ojalvo, L. Benard, N. Santoro, and J. W. Pollard. 2010. Genomic profiling of microRNAs and messenger RNAs reveals hormonal regulation in microRNA expression in human endometrium. Biol. Reprod. 82:791-801.

Li, X., Y. Zhang, H. Zhang, X. Liu, T. Gong, M. Li, L. Sun, G. Ji, Y. Shi, Z. Han, S. Han, Y. Nie, X. Chen, Q. Zhao, J. Ding, K. Wu, and F. Daiming. 2011. miRNA-223 promotes gastric cancer invasion and metastasis by targeting tumor suppressor EPB41L3. Mol. Cancer Res. 9:824-833.

Liu, C. G., G. A. Calin, B. Meloon, N. Gamliel, C. Sevignani, M. Ferracin, C. D. Dumitru, M. Shimizu, S. Zupo, M. Dono, H. Alder, F. Bullrich, M. Negrini, and C. M. Croce. 2004. An oligonucleotide microchip for genome-wide microRNA profiling in human and mouse tissues. Proc. Natl. Acad. Sci. USA 101:9740-9744.
Markou, A., E. G. Tsaroucha, L. Kaklamanis, M. Fotinou, V. Georgoulias, and E. S. Lianidou. 2008. Prognostic value of mature microRNA-21 and microRNA-205 overexpression in non-small cell lung cancer by quantitative real-time RT-PCR. Clin. Chem. $54: 1696-1704$

Mattmiller, S. A., C. M. Corl, J. C. Gandy, J. J. Loor, and L. M. Sordillo. 2011. Glucose transporter and hypoxia-associated gene expression in the mammary gland of transition dairy cattle. J. Dairy Sci. 94:2912-2922.

Moolmuang, B., and M. A. Tainsky. 2011. CREG1 enhances p16(INK4a)-induced cellular senescence. Cell Cycle 10:518-530.

Rottiers, V., and A. M. Näär. 2012. MicroRNAs in metabolism and metabolic disorders. Nat. Rev. Mol. Cell Biol. 13:239-250.

Silveri, L., G. Tilly, J. L. Vilotte, and F. Le Provost. 2006. MicroRNA involvement in mammary gland development and breast cancer. Reprod. Nutr. Dev. 46:549-556.

Stein, T., N. Salomonis, and B. A. Gusterson. 2007. Mammary gland involution as a multi-step process. J. Mammary Gland Biol. Neoplasia 12:25-35.

Tehler, D., N. M. Hoyland-Kroghsbo, and A. H. Lund. 2011. The miR10 microRNA precursor family. RNA Biol. 8:728-734.

Tili, E., J. J. Michaille, and G. A. Calin. 2008. Expression and function of micro-RNAs in immune cells during normal or disease state. Int. J. Med. Sci. 5:73-79.

Valastyan, S., A. Chang, N. Benaich, F. Reinhardt, and R. A. Weinberg. 2011. Activation of miR-31 function in already-established metastases elicits metastatic regression. Genes Dev. 25:646-659.

Valastyan, S., F. Reinhardt, N. Benaich, D. Calogrias, A. M. Szasz, Z. C. Wang, J. E. Brock, A. L. Richardson, and R. A. Weinberg. 2009. A pleiotropically acting microRNA, miR-31, inhibits breast cancer metastasis. Cell 137:1032-1046.

Wang, Z., Y. Li, S. Banerjee, D. Kong, A. Ahmad, V. Nogueira, N. Hay, and F. H. Sarkar. 2010. Down-regulation of Notch-1 and Jagged-1 inhibits prostate cancer cell growth, migration and invasion, and induces apoptosis via inactivation of Akt, mTOR, and NF- $\kappa \mathrm{B}$ signaling pathways. J. Cell. Biochem. 109:726-736.

Xu, G., C. Fewell, C. Taylor, N. Deng, D. Hedges, X. Wang, K. Zhang, M. Lacey, H. Zhang, Q. Yin, J. Cameron, Z. Lin, D. Zhu, and E. K. Flemington. 2010. Transcriptome and targetome analysis in MIR155 expressing cells using RNA-seq. RNA 16:1610-1622.

Zhang, C. Z., J. X. Zhang, A. L. Zhang, Z. D. Shi, L. Han, Z. F. Jia, W. D. Yang, G. X. Wang, T. Jiang, Y. P. You, P. Y. Pu, J. Q. Cheng, and C. S. Kang. 2010. MiR-221 and miR-222 target PUMA to induce cell survival in glioblastoma. Mol. Cancer 9:229. 